\title{
Benefits of trees
}

Forests play an important role in carbon storage and climate regulation, as well as supporting biodiversity. Restoration of lost and degraded areas is firmly back on the agenda with a recent UN announcement.

$\mathrm{M}$ arch this year saw the announcement that the coming decade, 2021-2030, has been declared the UN Decade on Ecosystem Restoration (https://go.nature. com/2NZGAh4). The target of restoring 350 million hectares of ecosystems globally will help to mitigate climate change, ensure food and water security, and preserve biodiversity.

In its simplest form, it sounds so straightforward - plant more trees to reduce atmospheric $\mathrm{CO}_{2}$ and achieve other benefits. It is the basis of the Bonn Challenge, launched in 2011 (http://www. bonnchallenge.org/), a voluntary initiative in which countries pledge to reforest with a global target of 150 million hectares by 2020 and 350 million hectares by 2030 . Recent analysis by Bastin et al. (Science 365: 76-79; 2019) shows it to be one of the most effective methods of $\mathrm{CO}_{2}$ mitigation, with six countries - Russia, the United States, Canada, Australia, Brazil and China - providing the potential for over $50 \%$ of a feasible 0.9 billion hectares of ecosystemsupported additional forest, which could store an extra 205 gigatonnes of carbon.

But reforestation is complicated, as Molly Hawes discussed in a Feature last year on the Bonn Challenge (Nat. Clim. Change $\mathbf{8}, 556-558 ; 2018$ ), with issues such as monocultures, which are typically quickly cut down, and potential societal tensions between policy for climate management and local needs for farming and other land use. Additionally, reforestation is not only about carbon storage, but also about preserving biodiversity and managing the hydrological cycle. A paper in this issue by Rebecca Senior and colleagues reports on how deforestation in the tropics is leading to the loss of connectivity. Connectivity in ecosystems is important for biodiversity, particularly as climate change is shifting suitable habitats for species. If there is no connectivity, then terrestrial species become trapped and are unable to shift. The authors show that $62 \%$ of tropical forests, or about 10 million square kilometres, are incapable of facilitating range shifts, and between 2000 and 2012 there was a loss of connectivity for over $27 \%$ of the surviving tropical forests.

As the climate changes, so do the challenges for tree and forest survival,

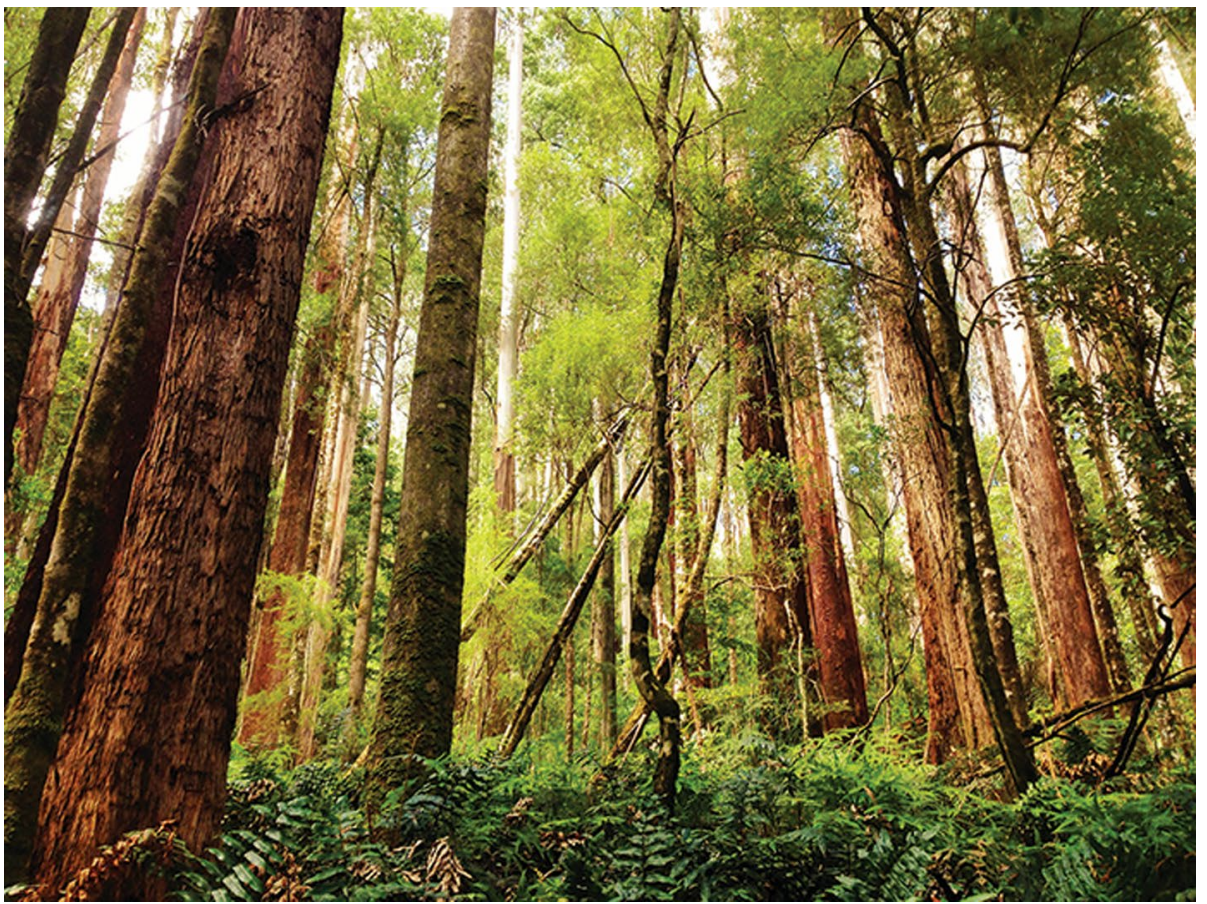

Credit: Ben Goode / Stockimo / Alamy Stock Photo

with rising temperatures and hydrological changes both acting as potential stressors. But the forests themselves can affect the climate; the Amazon is large enough to influence the hydrological cycle of the region, with transpiration in the southern Amazon triggering the transition from dry to wet season (J. S. Wright et al., Proc. Natl Acad. Sci. USA 114, 8481-8486; 2017). Further to this, rising atmospheric $\mathrm{CO}_{2}$ levels cause a change in physiological response (stomatal conductance and transpiration), which affects the hydrological cycles differently on a regional scale (G. J. Kooperman et al., Nat. Clim. Change 8, 434-440; 2018). Smaller-scale and more isolated forests are also subject to the effects of climate and climate change, with drought putting survival at risk, as discussed by Yan Jiang, Liming Zhou et al. for the Congo rainforest in a paper in this issue, along with other factors that may be detrimental to survival.

Just as for other terrestrial species, trees can be threatened by climatic zone shifts. Kyle Rosenblad and colleagues investigate island conifers in this issue and look at how their realized, fundamental and tolerance niches will match with future climates. Island species are particularly at risk, as they are isolated and have nowhere to go when their climate niche disappears. These studies highlight some of the threats to trees and forests that need to be considered in the push for reforestation and restoration.

The Bonn Challenge has been successful in securing pledges towards the stated goals, with 57 countries committing to reforesting about 170 million hectares. The recently announced forthcoming decade of restoration can hopefully build on these commitments and result in action. Although not as ambitious as the numbers laid out in the recent publication by Bastin et al., the target of 350 million hectares and potential removal of 26 gigatonnes of atmospheric $\mathrm{CO}_{2}$ may be more realistic and offer positive outcomes at local, regional and global scales.

Published online: 26 July 2019

https://doi.org/10.1038/s41558-019-0556-Z 